\title{
Expressões do conservadorismo na formação profissional*
}

\section{Conservatism expressions in the professional qualification}

\author{
Ivanete Boschetti \\ Professora do Departamento de Serviço Social e Programa de \\ Pós-Graduação em Política Social da UnB, Brasília, Brasil; doutora \\ e pós-doutora em Sociologia pela EHESS/Paris.
}

ivanete@unb.br

\begin{abstract}
Resumo: O artigo discute alguns traços que indicam o avanço ou a reatualização do conservadorismo no campo da formação do Serviço Social, tendo como pressuposto que o conservadorismo nunca esteve ausente da profissão e se alimenta no tempo presente por determinações societárias que fortalecem seu avanço. Trata-se, também, de apresentar uma análise crítica que possa ser um fermento para a indignação e para o estímulo à construção de formas coletivas e individuais de resistência.
\end{abstract}

Palavras-chave: Serviço Social. Conservadorismo. Luta social. Projeto Ético-Político Profissional.
Abstract: The article deals with some aspects showing the advance or updating of conservatism in the field of qualification for Social Work, and it has been understood that conservatism has never been absent from the profession, and that it has been fed by equity determinations strengthening its advance nowadays. It also presents a critical analysis to put forward indignation and stimulus to build up collective and individual forms of resistance.

Keywords: Social Work. Conservatism. Social struggle. Professional Ethical-Political Project.

\section{Introdução}

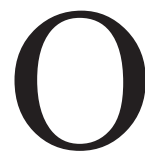

tema aqui abordado se situa na urgente e imprescindível reflexão sobre o avanço ou reatualização do conservadorismo no campo da formação e do trabalho profissional, não como lamento pessimista,

* Artigo elaborado a partir da palestra proferida no dia 11 de maio de 2015, na mesa "Espaços sócio-ocupacionais, lutas sociais e os desafios do Projeto Ético-Político do Serviço Social ante o conservadorismo", durante o $8^{\circ}$ Seminário Anual de Serviço Social, promovido pela Cortez Editora no Teatro Tuca, em São Paulo. 
mas como necessária análise crítica, realista, objetiva, com perspectiva de totalidade, única capaz de nos permitir destruir a pseudoconcreticidade do real (Kosik, 1986; Netto, 2009) e nos guiar na construção de lutas coletivas na direção do enfrentamento ao conservadorismo, com otimismo e indignação. Trata-se, portanto, de uma análise que não pode fugir à “dureza cor de giz" que representa o avanço insidioso do conservadorismo no Brasil e em todo o mundo. Trata-se, também, de apresentar uma análise crítica que possa ser um fermento para a indignação e para o estímulo à construção de formas coletivas e individuais de resistência.

Este é um tema recorrente no campo do Serviço Social, pois, não raro, análises conservadoras reiteram que existiria um fosso entre um projeto de formação baseado na teoria crítica marxista e uma prática profissional que não incorporaria essas referências teóricas e incorreria em trabalhos profissionais conservadores e reiterativos. Em outros termos, essas análises insistem em reafirmar que existe um enorme distanciamento entre uma vanguarda profissional que afirma e defende o Projeto Ético-Político - e aqui se incluem, sobretudo, docentes e direção das entidades - e uma base de assistentes sociais que estaria cada vez mais desconectada profissional e politicamente desse projeto. Esse distanciamento, dizem essas análises, resultaria de um avanço do conservadorismo no âmbito da prática profissional, que afastaria os(as) assistentes sociais da vanguarda profissional e estaria na base de um processo de derruição do Projeto Ético-Político Profissional.

Não se nega aqui a existência de um processo acelerado de avanço do conservadorismo em todos os campos: político, religioso, cultural, social e moral. Contudo, não se pode colar mecanicamente essa contraofensiva conservadora aos avanços e direitos conquistados nas últimas décadas, à existência de um "fosso" entre uma suposta formação teórica progressista e uma prática profissional conservadora. Tais análises parecem equivocadas, ou pelo menos limitadas, porque se assentam em uma suposta, e quase irreversível, dualidade dicotômica entre teoria e prática, entre vanguarda e base,

1. Expressão emprestada da música "Telhados de Paris", de Zélia Duncan. 
entre formação e intervenção profissional que, no limite, fortalecem e instrumentalizam o funcionalismo capitalista.

Considera-se aqui que o conservadorismo nunca deixou de permear a formação e o trabalho profissional. Por vezes explícita, por vezes implicitamente, sempre esteve presente, e também não é uma exclusividade do Serviço Social. Defende-se, portanto, que o conservadorismo não é um traço exatamente novo e atual que distanciaria uma "base" conservadora de assistentes sociais de uma suposta "vanguarda" progressista. O que orienta essas reflexões é uma perspectiva que defende que o conservadorismo é, e sempre será, alimento imprescindível da reprodução do capital, e por isso nunca sai de cena. Ou seja, é um alimento central para conservar a sociedade capitalista e sempre estará a seu dispor.

Foi na história de resistência e luta contra esse conservadorismo, que sempre quis subordinar e colocar a profissão a serviço da reprodução do capital, que o Projeto Ético-Político - em suas dimensões teórica, política, ética, legal e profissional — se constituiu como processo dinâmico e vivo, como expressão de luta contra o conservadorismo. Nesse processo, sempre viveu a dialética da convivência entre o pensamento conservador e a intenção de ruptura, como explica Netto (2011b). Essas reflexões iniciais intentam explicitar que não tratamos o avanço ou reatualização do conservadorismo como algo externo, ou fora do processo cotidiano da formação e do trabalho profissional. Ou seja, o conservadorismo nunca deixou de constituir o Serviço Social e, no momento presente, vem se reatualizando e se fortalecendo por algumas determinações societárias, sem as quais não seria possível entender esse avanço do conservadorismo, sinalizadas a seguir.

No campo econômico, a crise do capital ${ }^{2}$ reacende valores, políticas e medidas conservadoras, a exemplo da apologia ao livre mercado, a redução do papel do Estado na regulação das relações econômicas, o uso do fundo público para salvar o capital industrial e bancário em momentos de crise, a

2. Entendemos a crise atual como crise estrutural do capital, nos termos de Mandel (1990) e Mészáros (2009). 
mercantilização de serviços públicos, como luz, água, gás, telefonia. Todas essas medidas, largamente em curso sob o manto neoliberal desde a década de 1970, alimentam a competitividade, o individualismo e valores liberais conservadores. Mas também explicitam a incapacidade de o capitalismo viver sem crises e sem agudizar as desigualdades, violências e barbáries sociais. No campo social, a derruição do "Estado social" capitalista nos países capitalistas da Europa (Boschetti, 2012), garantidor de amplos direitos, provoca uma formidável precarização do trabalho, agudiza as desigualdades sociais, intensifica a pobreza e promove a perda de históricas conquistas sociais públicas, como trabalho, educação, saúde, aposentadoria, moradia, transporte. E, contraditoriamente, mostra que se o capitalismo precisa destruir os direitos para sobreviver, também não consegue viver sem o fundo público que o sustenta. No campo ideocultural, o avanço do fundamentalismo religioso e da intolerância acirra a discriminação, e variadas formas de opressão se manifestam de maneira cada vez mais violenta, mas também impulsiona novas formas de manifestação, organização e defesa de direitos de grupos sociais historicamente explorados e oprimidos, como mulheres, jovens, população afrodescendente e população LGBT. O que se quer sinalizar é que esses processos são determinações fundamentais do avanço do conservadorismo, mas também revelam suas contradições internas e nos chamam a compreendê-las como requisito para construir nossa intervenção no campo da formação, do trabalho e da política.

\section{Conservadorismo no Serviço Social: herança e resistência}

Como apontado anteriormente, o conservadorismo nunca esteve ausente na história da profissão. Análise instigante de Netto (2009) reitera que a profissão se gestou sob uma perspectiva conservadora com dois traços essenciais, entre outros. O primeiro se gestou como profissão da prática na divisão sociotécnica do trabalho, como resposta conservadora às expressões da questão social, destinada a prestar bens e serviços para assegurar a integração da classe trabalhadora na economia mercantil e para administrar uma 
política de manutenção da ordem do capital. Segundo, surgiu como profissão subalterna às Ciências Sociais, como profissão técnico-operativa, pragmática, avessa a formulações teóricas e à produção de conhecimento e sustentada teoricamente nas produções das Ciências Sociais, com ênfase no pensamento mais conservador (Netto, 2009, p. 147-148).

A reação a essa herança conservadora, nomeada pelo autor como "intenção de ruptura”, começa a se gestar timidamente nos anos 1960, ganha densidade a partir do final dos anos 1970, e forja coletivamente o Projeto Ético-Político, que tem no Congresso da Virada de 1979 sua mais emblemática expressão. Conforme sinaliza o autor, a reação ao conservadorismo e a construção do Projeto Ético-Político Profissional só foram possíveis pela conjunção de importantes processos. Primeiro, pela incorporação da teoria crítica marxista no âmbito da pesquisa e da produção de conhecimento pelo Serviço Social, que alçou a profissão à estatura das melhores produções críticas existentes sobre questão social, política social, direitos e emancipação, fundamentos do Serviço Social, ética, e lhe permitiu romper com o pensamento conservador predominante nas ciências sociais. Segundo, pela articulação do Serviço Social com movimentos sociais e partidos políticos anticapitalistas, o que lhe atribui um compromisso ético-político e profissional com as classes trabalhadoras, incrustado em nosso Código de Ética Profissional. Terceiro, pela superação do até então monopólio conservador que orientava a formação e o trabalho profissional, por meio do confronto crítico de ideias, valores, princípios e teorias. E quarto, pela construção de uma organização teórica-política-profissional - Conjunto CFESS/Cress, Abepss e Enesso - comprometida com valores e lutas anticapitalistas (Netto, 2009, p. 149).

Não foi sem luta que o enfrentamento ao conservadorismo se hegemonizou na profissão sob dois ângulos fundamentais. Na proposta de formação constante nas diretrizes curriculares da Abepss, fundada na teoria crítica marxiana e em suas categorias centrais: totalidade, historicidade, contradição, mediação e multideterminação dos fenômenos. E na regulação ético-política da profissão estabelecida no Código de Ética, na Lei de Regulamentação da 
Profissão e nas legislações daí decorrentes, que assumem ética e politicamente o compromisso profissional com a classe trabalhadora e com movimentos e lutas sociais, na perspectiva da emancipação humana, recusa a todas as formas de conservadorismo, de exploração, opressão e discriminação. ${ }^{3}$

Se o enfrentamento ao conservadorismo se hegemonizou e nos permitiu construir o Projeto Ético-Político Profissional, não significa que ele o extirpou da profissão, até porque esta se constitui, se desenvolve e se materializa em relações sociais permeadas e alimentadas cotidianamente pelas determinações sociais fundadas no pensamento conservador, já apontadas. Conforme mencionado, nossa luta contra o conservadorismo vem enfrentando, nas últimas três décadas, um contexto de forte ofensiva capitalista, no contexto de uma crise mundial, com mudanças que impactam diretamente na classe trabalhadora e nos seus projetos de superação da ordem burguesa.

\section{Influência do Protocolo de Bolonha e a contrarreforma do ensino superior}

Os traços que indicam uma reatualização do conservadorismo, aqui apresentados, não podem ser compreendidos como elementos endógenos e exclusivos do Serviço Social. Ao contrário, são tendências presentes em todas as áreas, fortemente alimentadas pela contrarreforma do ensino superior, forjada desde a década de 1990 no contexto da mundialização do capital e sujeição dos países às recomendações de organismos internacionais, como Banco Mundial (BM), Organização Mundial do Comércio (OMC) e Fundo Monetário Internacional (FMI).

As tendências de mercantilização do ensino superior ganharam fôlego a partir dos anos 2000, com a aprovação do Protocolo de Bolonha, ${ }^{4}$ que também incorporou muitas recomendações dessas organizações (BM, OMC, FMI),

3. As legislações e regulamentações profissionais estão disponíveis na página do Conselho Federal de Serviço Social (CFESS), em: < http://www.cfess.org.br/visualizar/menu/local/regulamentacao-da-profissao>.

4. As reflexões aqui apresentadas sobre a influência do Protocolo de Bolonha foram socializadas em palestra no Enpess (2012) e em artigo ainda não publicado. Para este texto, as reflexões foram atualizadas. 
como um requisito para a constituição da União Europeia. ${ }^{5} \mathrm{O}$ chamado Processo de Bolonha foi desencadeado pela Declaração da Sorbonne/Paris/ França (25 de maio de 1998) subscrita por quatro países - França, Alemanha, Itália e Reino Unido - , e consistia em uma declaração de intenção para estabelecer novas diretrizes para o ensino superior na Comunidade Europeia.

No ano seguinte, em 19 de junho de 1999, a cidade de Bolonha acolheu 29 ministros da Educação europeus, e na Declaração de Bolonha ficaram consagrados os princípios fundamentais que já haviam sido esboçados na Declaração da Sorbonne: legibilidade e comparabilidade dos diferentes graus acadêmicos (graduação e pós-graduação) atribuídos pelas universidades europeias, incluindo diplomas complementares; organização em três curtos ciclos de estudos: três anos para licenciatura/graduação, dois para mestrado e três para doutorado, com acesso direto e rápido; estabelecimento de um sistema de créditos passível de ser validado em todos os países da União Europeia; promoção da mobilidade dos estudantes, professores e investigadores; cooperação europeia para "garantir a qualidade do ensino, formação e investigação", e com estabelecimento de sistemas comuns de avaliação.

Os países integrantes realizam conferências bianuais nas quais avaliam o andamento das "reformas" e aprovam as cartas/declarações. Em 2009, outros 20 países foram convidados para compor o Fórum Político de Bolonha, entre eles o Brasil. Em março de 2010, os ministros da Educação e Ensino Superior dos atuais 47 países aderentes e convidados realizaram o Segundo Fórum Político de Bolonha e lançaram oficialmente o Espaço Europeu de Ensino Superior, com vista a consolidar o Processo de Bolonha. Se o Protocolo de Bolonha de 1999 objetivava formular um "Projeto de Reorganização do Ensino Superior na Europa" com o objetivo de "transformar a Europa na economia mais competitiva e dinâmica até 2010”, a constituição do Fórum vislumbra nitidamente a expansão mundial de suas

5. Informações oficiais sobre o Processo de Bolonha podem ser encontradas em: $<$ http://www.coe.int/t/ dg4/highereducation/EHEA2010/BolognaPedestrians_fr.asp>. Acesso em: 10 maio 2015. 
diretrizes, com vista a criar um sistema de ensino superior mundial estandardizado, de caráter global, para atender aos apelos da internacionalização da educação.

A proposta de mobilidade e sistema de créditos poderia ser interessante, se adotada com uma perspectiva de fortalecer a interlocução de pesquisadores e discentes, aprofundar os debates interdisciplinares e socializar conhecimento para além das fronteiras nacionais. Isso poderia fomentar o rompimento de barreiras e monopólios na produção e difusão do conhecimento. Contudo, o Protocolo de Bolonha, orientado por uma perspectiva nitidamente liberal, apresenta uma tripla face que, segundo Blanch (2010), em entrevista a Bianchetti (2010), vem provocando uma alteração estrutural do ensino superior no sentido de seu aligeiramento, competitividade e sujeição às demandas do mercado.

Segundo o autor, a face acadêmica, mais do que ampliar a socialização do conhecimento, tem provocado a estandardização/padronização como elemento para a integração dos jovens no mercado de trabalho, em um contexto de crise, com clara tendência de alinhamento da formação "por baixo", mais focada na aprendizagem e competências, bem como currículos mais curtos e flexíveis. A face econômica, em vez de fortalecer o histórico papel da universidade europeia na produção autônoma do conhecimento, se dobra às recomendações do FMI, BM, OMC, e sob um discurso de modernização, desburocratização e superação de uma "universidade arcaica", vem sustentando a mercantilização, o economicismo, a "empresarialização", o gerencialismo e a subordinação ao mercado e ao sistema produtivo. E a face política-cultural cria e consolida a cultura de uma nova concepção de universidade, de um novo "modelo" de organização, de estrutura, de planos de ensino, pesquisa e avaliação: essa cultura sustenta que uma boa universidade deve ser barata (menos anos, menos custos), rápida (cria uma espécie de fast universidade, e defende que se faz o mesmo em menos anos), padronizada (mesmo formato em diferentes realidades), deve ter financiamento autossustentável (graduação barata, curta e rápida, mestrados curtos e pagos para uma elite, doutorados curtos para docência e/ou pesquisa acadêmica e 
para demandas do mercado); mercantilmente adaptada às exigências de expansão e acumulação do capital, sobretudo em contexto de crise do capital.

Essas três faces propostas pelo Processo de Bolonha para as universidades públicas fundamentam e alimentam o avanço do conservadorismo no âmbito da formação e apontam para um retrocesso nas históricas lutas para construir uma formação profissional crítica, com perspectiva de totalidade e comprometida com a transformação social. Muitas dessas tendências já se faziam presentes no ensino superior brasileiro desde meados da década de 1990, com a entrada em vigor da Lei de Diretrizes e Bases da Educação (LDB) em 1997. Contudo, o ingresso do Brasil no Fórum Político de Bolonha em 2009 parece ter contribuído para acelerar e aprofundar a incorporação dessas recomendações nos processos de contrarreforma do ensino superior no Brasil, com graves implicações para o ensino em todos os níveis. As mudanças em curso desde 1996, algumas indicadas na Lei de Diretrizes e Bases da Educação, foram intensificadas com a proposta de "reforma universitária” do governo Fernando Henrique Cardoso (PSDB), seguidas pelas dos governos Lula e Dilma (PT).

Todas as medidas previstas na LDB — exame nacional de curso, mestrados profissionalizantes, substituição dos currículos mínimos por diretrizes curriculares, cursos sequenciais, ensino a distância em todos os níveis seguem as diretivas do Protocolo de Bolonha, no sentido da privatização das políticas sociais, de favorecimento da expansão dos serviços privados, de diversificação e massificação do ensino e de reconfiguração das profissões.

A expansão dos cursos e matrículas favorece assustadoramente o ensino privado lucrativo. De acordo com o Censo do Ensino Superior, publicado pelo Ministério da Educação (MEC, 2013), em 2013 o Brasil contava com 7.037.688 alunos matriculados em 31.866 cursos de graduação. Esses cursos se concentravam em 2.416 instituições, sendo a esmagadora maioria privada (2.112 ou 87,41\%) e somente 304 (12,59\%) públicas.

O ensino a distância vive um processo de expansão acelerada em todos os níveis: educação básica, educação de jovens e adultos, educação especial, educação profissional e educação superior. Esta última abrange cursos se- 
quenciais, graduação, especialização, mestrado e doutorado. O ensino de graduação a distância (EAD) está em momento de franca expansão no âmbito das instituições privadas e, em menor ritmo, também nas universidades públicas. De acordo com o mesmo Censo do Ensino Superior de 2013, o EAD conta com mais de 1,2 mil cursos a distância no Brasil e concentra aproximadamente $15 \%$ das matrículas de graduação. ${ }^{6}$

O Serviço Social concentra o terceiro maior contingente de matrículas nos cursos de graduação a distância, conforme Censo do Ensino Superior, depois de Pedagogia e Administração: Pedagogia concentra 34,2\% das matrículas em EAD; Administração responde por 27,3\%; Serviço Social, por $8,1 \%$; Letras vem em seguida, com 5,9\%; Ciências Contábeis fica com 3,6\%; Matemática, com 2,8\%; Ciências Biológicas na sequência, com 2,3\%; História, com 2,0\%; Comunicação Social, com 1,9\%; e Ciências Ambientais apresentam $1,6 \%$.

Essa expansão atinge diretamente o Serviço Social, que saltou de 70 mil profissionais em 2006 para 135 mil ao final de 2013 e 150 mil em 2015, ou seja, em nove anos (2006-2015) alcançou um quantitativo superior àquele formado em sete décadas (1936-2006). Inegavelmente, o EAD é o maior responsável por esse crescimento assustador, acompanhado de baixa qualidade, com formação rasa e superficial, conforme amplamente denunciado pelo CFESS, em especial no documento "Sobre a incompatibilidade entre graduação a distância e Serviço Social”.?

Nesse contexto regressivo, mais do que nunca se mostra imprescindível identificar os traços atuais do conservadorismo, como uma condição para seguir lutando contra seu espraiamento e em defesa das históricas conquistas do nosso Projeto Ético-Político. No breve espaço deste texto, destacamos a seguir alguns traços contemporâneos do conservadorismo no âmbito da formação profissional.

6. Dados disponíveis em: $<$ http://portal.inep.gov.br/visualizar/-/asset_publisher/6AhJ/content/matriculas-no-ensino-superior-crescem-3-8>. Acesso em: 30 mar. 2015.

7. O documento foi publicado originalmente em 2010 e sua segunda edição atualizada foi republicada em 2011. Disponível em: <http://www.cfess.org.br/arquivos/perfilas_edicaovirtual2006.pdf>. 


\section{Traços do conservadorismo na formação profissional}

Em instigante artigo, Netto (2009) apresenta a hipótese de que o pensamento conservador, afastado (melhor seria abafado) teoricamente sob a hegemonia do pensamento crítico de viés marxiano após a década de 1970, volta agora com força total, metamorfoseado, e atravessa novas dimensões do fazer profissional. Diz o autor: "Vê-se, pois, que, lançada à rua pela porta da frente, a velha representação do Serviço Social como 'profissão da prática' invade a nossa casa pelas janelas do fundo" (Netto, 2009, p. 161). A "porta do fundos" a que ele faz referência é a reatualização do pragmatismo, da ênfase no Serviço Social como profissão da prática, da busca por metodologias conservadoras no âmbito das Ciências Sociais, sobretudo aquelas assentadas no pensamento pós-moderno.

De acordo com o autor, o que se pretende desenvolver aqui é a ideia de que essa reatualização do conservadorismo no âmbito do "fazer profissional" está intimamente relacionada, e mesmo determinada, pelo avanço de certos traços conservadores na formação profissional. A incorporação do pensamento pós-moderno nos currículos, à revelia das Diretrizes Curriculares, tem revitalizado alguns traços conservadores balizados a seguir.

O metodologismo ressurge sob a forma de ênfase no tecnicismo e legalismo positivista, como elemento crucial na formação e na pesquisa, em detrimento do questionamento, da crítica, da grande política como elementos fundamentais do pensamento crítico. Fortalece-se a suposição de que uma boa técnica, ou um arsenal de técnicas, pode substituir a análise crítica e a ação política coletiva na transformação do real. Daí decorrem elaborações teórico-metodológicas orientadas por abordagens conservadoras, prescritivas ou descritivas, que realçam o empirismo e rebaixam o pensar crítico e a intervenção comprometida com a transformação coletiva.

O teoricismo acrítico é outro traço conservador e se caracteriza como conceituação operacional e adoção de categorias pós-modernas e conserva- 
doras das Ciências Sociais (sobretudo Sociologia, Psicologia e Antropologia), ${ }^{8}$ que aceitam sem criticidade as teses do "fim da história", ou mesmo teorias que defendem as relações mercantis, ainda que sob a égide da social-democracia. Trata-se da ênfase às abordagens abstratas que não desvendam o real em sua totalidade e reiteram a conservação de relações mercantis e mercantilizadas. Abordagens que supõem, falsamente, que a neutralidade é possível e não percebem (ou escondem) que a suposta neutralidade ou acriticidade é uma poderosa arma da conservação. O teoricismo acrítico incorpora no arcabouço teórico do Serviço Social categorias próprias do arsenal conservador, como integração, vigilância, vulnerabilidade, empoderamento, justiça social, terceiro setor, entre outras.

$O$ aligeiramento da formação e da pesquisa é um traço absolutamente contemporâneo. O expansionismo superficial de cursos é extremamente funcional ao conservadorismo, pois conserva e mesmo agudiza a perspectiva de formação funcional ao mercado e subordina os conteúdos profissionais à demanda do mercado, ou seja, do capital.

O pragmatismo alimenta um tipo de formação, mas também de trabalho profissional, baseado na filosofia utilitarista, no imediatismo, no famoso discurso de que "na prática a teoria é outra". Tal postura leva à negação da teoria, à adesão ao praticismo acrítico, à ação imediatista, desprovida de compromisso político com a transformação estrutural das relações socioeconômicas. É preciso compreender que nenhuma teoria "se aplica" ao e no real. A teoria é o real captado pelo pensamento (o concreto pensado), que busca explicar os fenômenos da realidade em uma perspectiva de totalidade. A teoria pode subsidiar a ação profissional e/ou política na transformação do real, por isso é uma mediação para a ação. Teoria não é e nunca será uma receita de intervenção profissional.

$O$ voluntarismo revela um subjetivismo descolado da objetividade e das múltiplas determinações do real. Alimenta-se na pobreza teórica que

8. Não estou aqui dizendo que a Sociologia, a Antropologia e a Psicologia são conservadoras, mas que o teoricismo acrítico no Serviço Social incorpora algumas categorias de cunho conservador presentes nessas disciplinas. 
considera desnecessário estudar, ler, conhecer em profundidade as teorias e seus autores. Favorece a ação pragmática individualizada e a responsabilidade pessoal e profissional no trato das expressões da questão social. Provoca o esvaziamento do pensar crítico, das lutas sociais coletivas e favorece a doce ilusão da "competência técnica" como suficiente para a "resolução de problemas".

O contentamento com o possibilismo é típico do conformismo com mudanças no quadro das instituições capitalistas existentes. É a concordância com a "melhoria" social possível nos marcos do capitalismo. O "reformismo" social-democrata do pós-Segunda Guerra Mundial possibilitou a ampliação de alguns direitos no capitalismo, mas jamais se propôs a emancipar a humanidade das relações de exploração capitalista, acabando por se render ao possibilismo contrarreformista. A perspectiva de Serviço Social que se contenta com o avanço dos direitos no capitalismo se localiza nos marcos do reformismo social-democrata, mas a perspectiva de Serviço Social que se curva e incorpora as orientações neoliberais de privatização, focalização, universalismo básico e tantos outros modismos se localiza nos marcos do neoliberalismo contrarreformista, sendo meramente possibilista. Ambas são poderosas armas da conservação da ordem burguesa, ainda que possam ter algumas diferenças entre si. Tanto o reformismo social-democrata quanto o possibilismo neoliberal alimentam posições e intervenções que incorrem em práticas conservadoras, como a focalização, a seletividade, a integração, o assistencialismo, o individualismo, a competitividade, o quantitativismo, o fortalecimento do capital humano.

Muitos desses traços conservadores são fomentados pelo desencanto e pelas sucessivas perdas sociais históricas, submetidas à barbárie neoliberal. Enfrentá-las e superá-las exige construir estratégias coletivas pautadas no Projeto Ético-Político Profissional, que possibilitou ao Serviço Social alcançar sua maioridade teórico-política.

Por isso, debelar esses traços conservadores requer recusar a formação aligeirada, acrítica e tecnicista e defender a formação na perspectiva de totalidade sem nenhuma concessão ao possibilismo e ao reformismo. Exige 
recusar os modismos tecnicistas e pragmáticos na formação e no trabalho profissional e defender firmemente o trabalho como espaço de fortalecimento dos direitos da classe trabalhadora, direitos entendidos como mediação para acumular forças, para fortalecer as lutas universais pela libertação das relações mercantis. No âmbito especificamente do Serviço Social, o desafio de reafirmar nosso Projeto Ético-Político é mais necessário do que nunca, pois não podemos recuar diante da ofensiva conservadora e retroceder nas conquistas alcançadas por tantas gerações.

O crescimento acelerado da profissão não pode fagocitar esse precioso patrimônio construído coletivamente, que é o Projeto Ético-Político Profissional. Por isso, a formação e o trabalho profissional devem ser oxigenados permanentemente pela indignação com a barbárie, pela recusa ao naturalismo das coisas e pelo otimismo e convicção de que a história é construída por sujeitos, homens e mulheres, alimentados pelo conhecimento teórico da realidade.

Recebido em 26/6/2015 - Aprovado em 28/7/2015

\section{Referências bibliográficas}

BRASIL/MEC. Censo da Educação Superior. Disponível em: <http://portal.inep.gov. br/web/censo-da-educacao-superior $>$. Acesso em: 30 mar. 2015.

BOSCHETTI, Ivanete. A insidiosa corrosão dos sistemas de proteção social europeus. Serviço Social \& Sociedade, São Paulo, n. 112, 2012.

BLANCH, Josep M. O Processo de Bolonha e a intensificação do trabalho na universidade: entrevista concedida a Lucídio Bianchetti. Educação Social, Campinas, v. 31, n. 110, p. 263-285, 2010. Disponível em: <http://www.scielo.br/pdf/es/v31n110/14.pdf> . Acesso em: 10 maio 2015.

KOSIK, Karel. Dialética do concreto. 4. ed. Rio de Janeiro: Paz e Terra, 1986. 
MANDEL, Ernest. A crise do capital. São Paulo: Ensaio/Ed. da Unicamp, 1990.

MÉSZÁROS, Istvan. A crise estrutural do capital. São Paulo: Boitempo, 2009.

NETTO. José Paulo. Introdução ao método na teoria social. In: . Serviço Social: direitos sociais e competências profissionais. Brasília: CFESS/Abepss, 2009. p. 667-700. . As perspectivas teórico-metodológicas contemporâneas no Serviço Social. In: . O trabalho social França-Brasil. São Paulo: Sesc/CBCISS. 2011a. p. 145-162. . Ditadura e Serviço Social: uma análise do Serviço Social no Brasil pós-64. São Paulo: Cortez, 2011b. 